\title{
O PAPEL DOS ORGANISMOS NÁO-GOVERNAMENTAIS NO DIREITO COMPARADO
}

\author{
THE ROLE OF NON-GOVERNMENTAL ORGANIZATIONS IN \\ COMPARATIVE LAW
}

\author{
Antonio Elian Lawand Junior ${ }^{\mathrm{I}}$ (1) \\ Luiz Sales do Nascimento ${ }^{\text {II }}$ (1)
}

\begin{abstract}
I Universidade Católica de Santos, Santos, SP, Brasil e Universidade São Judas Tadeu, São Paulo, SP, Brasil.

Doutorando em Direito. E-mail: antonio.lawand@gmail.com
\end{abstract}

II Universidade Católica de Santos, Santos, SP, Brasil. Doutor em Direito. E-mail: profsalesorientador@bol.com.br

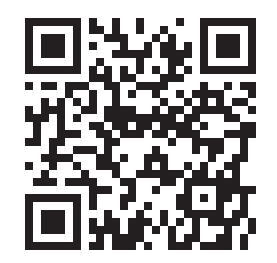

DOI: http://dx.doi.org/10.31512/rdj.v20i38.164

Recebido em:20.08.2019

Aceito em: 30.06.2020
Resumo: $\mathrm{O}$ presente trabalho tem por finalidade situar a função das Organizaçôes Não-Governamentais na construção da finalidade do Direito Comparado, quando o objeto deste for a norma jurídica de Direito Internacional, em temas/ problemas de interesse Global. Para este intuito, primeiro tomamos o processo de formaçáo das normas jurídicas internacionais e a colocamos: a) diante de um problema/ objeto global; e b) no processo dualista de internalização. Identificamos, neste longo proceder, as janelas de maior permeabilidade do processo de formação da norma jurídica e as entidades (nominadas ou náo) capazes de nutrir estas fases permeáveis. Após, imiscuímo-nos no papel que o Direito Comparado tem na efetividade da norma interna, homogeneizando-a entre povos e Estados como norma internacional de origem, através da análise e escolha de elementos infraestruturais das sociedades quelheécompetente. Por fim, discutimos este proceder do Direito Comparado com a atuação das Organizaçóes Não-Governamentais na qualidade destas como agentes preponderantes à realização do Direito Comparado em âmbito de Direito Internacional. Concluímos que as Organizaçóes Não-Governamentais têm papel relevante de uniformizaçáo em matrizes de direito internacional aberto, com pontos específicos e importantes de atuação, relacionados com sua condição reconhecida de ator e sujeito de direito internacional. A pesquisa foi desenvolvida com base bibliográfica e documental, em métodos hipotético-dedutivo e dialético.

Palavras-chave: Direito Internacional. Direito Comparado. Organizaçóes Não-Governamentais. Norma Jurídica Internacional.

Abstract: The aim of this paper is to describe the role of NGO
in Comparative Law work at its object of International Law
in Global issues. Concerning this objective, we approach the
building process of international law and face it off: a) a global
issue/objective; and b) in a dualist juridical system. During
this procedure we spotted gaps which laws external influence
shall be bigger than any other phase and entities capable of 
act on these gaps. After, we explore Comparative Law role at national rule effectiveness, giving it a pattern between nations and States of a unique international rule source, through analysis and choice of infrastructural social elements. In the end, we discuss this Comparative Law procedure looking for a syntax with NGO actors as its agents in International Law. We concluded that NGOs have a relevant role in create uniform interpretation in an open matrix of international law, with stressed acting points related to its recognition as international law actors and subjects. This research was developed in bibliographical and documental basis, in hypothetic-deductive method and dialectics.

Keywords: International Law. Comparative Law. NonGovernmental Organizations. International Rule of Law.

\section{Consideraçóes iniciais}

O presente trabalho tem por finalidade mapear (ainda que brevemente) a função das Organizações Não-Governamentais ("NGO”) na construção da finalidade do Direito Comparado, quando este for solicitado a manipular a norma jurídica de Direito Internacional, em temas/problemas de interesse Global.

O interesse não é fora de contexto e guarda sua importância: as antigas formas preceituais internacionais de lidar juridicamente com os problemas ambientais (complexos e classificados, classicamente, como wicked problems) falharam. Em função desta falha, a Sociedade Internacional (como tal dogmaticamente classificada pela doutrina) se expande para reconhecimento de novos atores, para que eles tragam conceitos, nutram interpretações ou apresentem as novas soluçôes e abordagens que possuam. Também pela perspectiva da fonte contratual do direito internacional podemos checar a necessidade de transformação na qual as NGO importam: novos formatos preceituais normativos (ou ainda, novos usos do antigo formato) para avançar no cenário jurídico internacional, em função de uma necessidade de multipla governança.

Para este intuito, de mapear as funções das NGO utilizamos o seguinte roteiro, que refleitiu nosso processo de experimentação: a) tomamos a Sociedade Internacional em seu conceito mais fechado e mais conservador, em função da Paz de Vestfália/1648; b) um problema comum a ser resolvido por esta Sociedade Internacional (e.g. o problema ambiental global); c) o direito pos-positivista como base e fundamento; d) o processo de formação das normas jurídicas internacionais como ponto de partida de nossa análise; e) exploramos os pontos deste processo de formação das normas jurídicas internacionais no qual os atores NGO são capazes de atuar; f) analisamos o cenário e as necessidade de integração das NGO no Direito Internacional, como veículo facilitador do Direito Comparado. 
Ressaltamos que também descrevemos criticamente o processo de internalização e materialização desta norma internacional, observando os cuidados inerentes ao Direito Comparado, quando visa sua perfeita harmonização com o Direito Interno (no caso de aplicação da Teoria Dualista), com vistas à sua materialização e efetividade nos termos internacionalmente propostos. Neste processo, tornamos a explorar os pontos deste processo produtivo nos quais os atores Organizaçóes Não-Governamentais são capazes de atuar e que papel desempenham.

Por fim, analisamos o porquê destes atores Organizações Não-Governamentais assumirem estes papéis em ambos os processos, em especial, no que tange a instrumentalizar os objetivos do Direito Comparado. De todo, extraímos conclusóes em tópico apartado e articulado.

Utilizamo-nos de método hipotético-dedutivo para a consecução e encadeamento de ideias, conceitos e conclusóes neste trabalho expostas. A metodologia de pesquisa foi predominantemente bibliográfica, com incursôes necessárias em legislações, julgado e documentos históricos outros.

\section{Da construção da norma jurídica internacional pela sociedade internacional}

"Tragedy of Commons" foi o label utilizado por HARDIN (1968, 1243-1248) em seu celebrado paper homônimo, no qual explora que um objetivo comum a diversos atores, ainda que alcançar este este objetivo distribua benefícios a todos, não é motivação suficiente a que os atores busquem individualmente este objetivo, quanto mais cooperem entre si para o intento.

A aplicar o conceito à espécie, temos que a globalização de problemas (e.g. os de natureza ambiental, os de natureza energética) (CARLARNE, 2014, 8-9) denotou em duas consequências no direito: a) uma importância das normas internacionais sobre temas globais crescentes (VIDAL , 2012, n.p.); e b) num câmbio de orientação acerca da forma como o preceito normativo (sobre o tema global em específico) é formulado, saindo de modelagens de comando e controle, vigiar e punir, codificaçóes e estatutos, procedimentos e condutas, para uma modelagem de metas e checkpoints (CARLARNE, 2014, 24-32), com uma ressignificação da importância da soft law.

Em breve digressão, no sistema jurídico internacional existem categorias de normas jurídicas. As chamadas tradicionalmente (e impropriamente) soft law compóem normas jurídicas de efeito de ordem política e/ou moral, e não vinculantes (non-binding), propriamente. Diz-se não ter um efeito vinculante típico, mas ainda manter um efeito regulador, direcionador de condutas em certo nível, em função das consequências de sua ruptura/novidade no universo normativo, e por ser justificativa jurídica capaz de 
direcionar as atitudes dos sujeitos de direito internacional. (BEYERLIN ET MARAHUN, 2011, 289-291).

Tornando à questão global, a Sociedade Internacional debatia-se ante o problema global e carecia açóes que tornassem efetiva a gestão do patrimônios comuns (e.g. ambiental): a) a Sociedade Internacional aferrava-se a interpretaçóes restritivas, em função de sua hierarquização e seus sujeitos de direito, em derivação a interpretaçóes conservadoras de Soberania derivadas dos Tratados de Münster e Östnabruck/1648 (ABI-SAAB, 1987, 51-53) (SCHRIJVER, 2007, 379-380), muito em função da própria crise (nos anos 80 e 90) que o instituto jurídico-político do Estado (GIDDENS, 2001, 450-452); e b) apontavam necessidades normativas de cunho preceitual acerca de uma suposta carência de uma Gründnorm que fundamentasse, articulasse e integrasse o Direito Internacional em busca de um resultado ambiental (ABI-SAAB, 1987, 46, 122) (CARLARNE, 2014, 29). Em explicação do conceito (embora coloquem o conceito de Sociedade Internacional como aberto e sujeito a definições não juridicamente balizadas), para fins didáticos da exibição da construção do pensamento deste ensaio, utilizaremos esta expressão em conceito fechado:

une communauté internationale universelle reflétait également les structures plus ou moins symétriques ou égalitaires des rapports juridiques (et des rapports de force) existants, du moins entre les puissances européennes et les peuples connus de l'ancien monde; ce qui impliquait qu'on les considérait comme des interlocu-teurs valables sur le plan international, c'est-à-dire comme des com-munautés politiques autonomes et d'une certaine manière égales. (ABISAAB, 1978, 51)

Tornando ao nosso tubo de ensaio ambiental, os problemas ambientais colocaram sob foco os Estados Nacionais e as vicissitudes que os levaram à crise contestatória de suas utilidades e funçóes: grande demais aos pequenos problemas, pequeno demais aos problemas globais (GIDDENS, 2000, 23).

Todavia, a asserção não exige uma postura de abolição dos sujeitos da sentença! Pensemos pela perspectiva do objeto da oração (CARLARNE, 2014, 33-41): os problemas. E diferentes problemas exigem abordagens diferentes.

Em outras palavras, o problema ambiental global, em suas deversas facetas, exige uma gründnorm? A autora revela que problemas ambientais, pela sua peculiaridade de gestão de risco global de multiplos atores desiguais, não exige uma gründnorm e, por vezes, ela atrapalha (CARLARNE, 2014, 42-45).

Assim, analisemos a gênese da norma jurídica (internacional ou não): qualquer norma jurídica tem por matriz de produção aquela evidenciada pelo pós-positivismo (DWORKIN,1985, 77-82), qual seja: o entendimento atual do Direito abandona os conceitos de um Direito impermeável, hermético, do "dever ser", elementos do ideário (neo)positivista e a norma jurídica passa a ser um construído, derivado do preceito e dos 
valores que regem a sociedade no qual ocorreu o conflito ou a oportunidade de aplicar o Direito.

Em pormenores, o que se discute hoje é a função do Direito em comunicar aquilo que "é", na dinâmica do choque dos fatores reais de poder, dos sujeitos (ainda que não de direitos, como se verá). Nessa ideia, a análise dicotômica dos preceitos em relação ao seu conteúdo mandamental (normas) permitiu a identificação de uma atual concepção de Direito. Assim sendo, o processo de produção da norma jurídica exige permeabilidade a elementos extranormativos (DWORKIN, 1985, 44-46), o que se dá na interpretac冈ão do preceito. Em outros termos, a norma jurídica é produto do conteúdo do signo normativo, e não no signo em si (e.g. uma lei, em sentido estrito) (DWORKIN, 1985, 62-63).

Portanto, acerca do processo de produção destas normas jurídicas, observa-se que ela é permeável a fatores extrajurídicos em seus dois pontos específicos cruciais, quais sejam: a) no momento da produção/redação do preceito; b) no momento da interpretação pela Corte e formulação da norma/precedente.

Sobre esta permeabilidade abordemos a da Corte, primeiramente. Dworkin (1985, 62-63) aponta neste aspecto que o paradigma (do que ele chama "Ético") vigente (i.e., afeito ao tempo da observância da norma na Corte) informará a construção da norma. É da interpretação do preceito, sob ótica e jugo deste paradigma, que surgirá uma norma jurídica, em qualquer de suas modalidades (princípios, regras ou políticas públicas).

Esta é uma primeira janela aos grupos de pressão em exercer sua influênicia à norma jurídica: por vias até institucionais, principalmente mas não exclusivamente, os grupos de pressão (i.e. fatores reais de poder) podem informar a Corte acerca do conteúdo deste "paradigma Ético vigente" (LAWAND JUNIOR, 2012, 208-212) (GAUTIER, 2016, n.p).

Já sobre a permeabilidade da origem do preceito (parlamentos, órgãos técnicos, órgãos executivos), Amaral (1997, 127-138) enuncia o papel dos grupos de pressão (lobby, advocacy, consultas públicas, etc.) como preponderante na escolha pública de um determinado formato/redação normativo/preceitual em detrimento de outros.

Este conceito é aplicável à formulação das normas jurídicas de direito internacional, em especial aquelas que tratam de problemas globais? A resposta é positiva, especialmente tratando-se de Direito Ambiental Internacional conforme as conclusões das análises de Beyerlin et Marahun $(2011,256)$.

Repare que em todas as normas jurídicas, a construção de seus elementos fundamentais de produção (preceito e interpretação da Corte) são sujeitos à influenciação por informações trazidas por agentes externos à produção da norma jurídica. Foram estes agentes que identificaram aos atores nominalmente produtores (de norma e preceito): a) o problema; b) os dados e hipóteses de solução do problema; e c) o "paradigma ético" 
vigente de Dworkin (na carência momentânea de melhor expressão) a ser aplicado ao preceito.

Repare mais: que estes agentes externos são muito mais que governos subnacionais ou locais (para utilizar da mesma nomenclatura dada pelas Naçôes Unidas). Em sua (natural) maioria são organizações não-governamentais (ONG), definidas como "entidades que participam e se manifestam na sociedade internacional como forças de pressão, e, apesar de possuírem personalidade jurídica de direito interno, o Direito Internacional lhes defere certo status jurídico" (GUERRA, 2016, n.p.). Esse status, por sua vez, variará conforme a arena dialética na qual a entidade pretende influir. ${ }^{1}$

Conclui-se que é aplicável a teoria geral da formação da norma jurídica às normas de direito Internacional que tratam de problemas Globais.

\section{A missão específica do Direito comparado em Direito internacional}

Ainda que aplicável a teoria geral da formação da norma jurídica às normas de direito Internacional que tratam de problemas Globais, temos a questão de relacionála às teorias Dualistas do Direito Internacional. Para finalidade deste trabalho, cumpre compreender que a Teoria Dualista de Direito Internacional pressupóe uma Dicotomia não-homogênea entre o Direito Internacional e o Direito Interno (nacional), como duas ordens jurídicas distintas, com prevalência do Direito Interno sobre o Internacional, na medida em que o sujeito de direito internacional primaz (i.e. o Estado Nacional) ainda que assine o documento preceitual jurídico internacional (e.g. um Tratado), deve ratificalo no direito interno como forma de tornar a norma internacional aceite e aplicável em sua jurisdição (Poder decorrente da Soberania), modificando o direito interno. (ARANGIORUIZ, 1990, 444-451).

A suma deste diálogo (aplicabilidade da norma jurídica internacional em âmbito interno soberano) versa, em termos gerais, sobre a formação da norma jurídica nacional a partir da norma jurídica internacional (ainda que soft law).

Retornemos ao nosso objetivo comum ambiental global e pensemos, exatamente, na formação mais comum e moderna de norma jurídica internacional, a soft law que trabalha objetivos e checkpoints, tal qual os Objetivos do Desenvolvimento Sustentável, conforme aprovados pela Resolução 70/1, da Assembleia Geral das Naçóes Unidas, ou as "ODS".

Pensemos agora no nível da Sociedade Internacional e seus membros: para que um Estado soberano assuma as ODS em âmbito interno dependerá, alternativamente: a)

1 E.g. a) Artigo 34.2, do Estatuto da Corte Internacional de Justiça prevê a participação das ONG como amicus curiae na Corte; b) Artigo 71, da Carta da Organização das Nações Unidas, de 1945, prevê a participação das ONG como consultores especializados e ainda define os critérios (objetivos e temáticos) para que seja definida como uma ONG apta a tanto. 
de um procedimento parlamentar que o assuma em legislação interna; ou b) da assunção desta norma por meio de um procedimento judicial especial (exequator) afeito a assunção de julgamentos de cortes estrangeiras; c) da assunção desta norma por meio de um procedimento judicial como seu fundamento decisório.

Todavia, há uma quarta e quinta possbilidade: d) da assunção desta norma (se assim possível pelo crivo constitucional nacional) por entidades subnacionais e locais (e.g. municípios, Estados, Regióes Metropolitanas); e e) da assunção desta norma (idem) por entidades náo-governanmentais (com ou sem fins lucrativos) como paradigma de suas condutas, processos de produção, conquista de mercados e, até, modo de viver.

A soberania garante que os processos internalizadores "a", "b" e "c", supra, sejam suficientes a inovar o direito interno. Mas não se olvide do poder e potência das formas "d" e "e", supra, ao alcançar, politicamente, o mesmo intento. Como exemplo subnacional e local, temos que o Estado de São Paulo (ainda que, por vezes, não seguido ou secundado pela União) tem vanguarda em assumir normas de direito ambiental (em especial, no âmbito de meio ambiente), por situação de distribuição específica de competências constitucionais, tal como ocorreu no âmbito de políticas de mudanças climáticas. Neste caso, o Estado de São Paulo (subnacional) promulgou a Lei no 13.798/2009, assumindo os valores da Convenção Quadro de Mudanças Climáticas das Naçóes Unidas 50 dias antes que a própria União Federal (i.e. o Estado-Nação) a assumir os mesmos valores, da mesma Convenção Lei no 12.187/2009.

E quanto às ONG? Conforme o exemplo subnacional ensinou, pensar a promoção da norma jurídica internacional em âmbito interno necessita de um pensar reverso, qual seja: tomando em consideração a coletividade a que se destina a aplicação e efetividade da norma jurídica, que estruturas internas/nacionais/subnacionais são úteis e/ou suficientes à construção de uma determinada norma jurídica? Que tipo de Corte? Que tipo preceito (forma e conteúdo)? Mas se a norma jurídica internacional está posta, este problema é realmente relevante? Respondemos que sim, e veja-se o porquê no caso abaixo:

Como dito antes, a Sociedade Internacional é fragmentária e desigual entre seus próprios sujeitos de direito (Estados Soberanos). O Princípio de Direito Ambiental Internacional de Common But Differentiated Responsibilities ("CBDR") ou Proporcionalidade das Obrigações Internacionais surge no ambiente de troca de eixo de discussão internacional (de Leste-Oeste para Norte-Sul, nos anos 70, do sec. XX) com dupla função: a) estimular adesão universalista dos acordos em matéria de meioambiente; b) reconhecer que nem todos os países (especialmente, os do Sul) alcançaram o mesmo grau de desenvolvimento (econômico, em especial) e que, diante de um problema global e comum, as responsabilidades devem ser partilhadas pela régua da capacidade de agir de cada ator, e não da partição das responsabilidades em critérios matemáticos 
absolutos, como forma de gestão mais adequada à solução do problema (BEYERLIN ET MARAHUN, 2011, pp.60-61).

Como princípio que é (evidenciado sobretudo no Princípio 7, da Declaração do Rio - Rio/92), trata-se de um mecanismo de otimizaçấo de cumprimento de seu conteúdo, na medida da máxima possibilidade.

E o problema reside justo aí, sobre o "ótimo" que servirá de lastro à construção da norma princípio. Divergem Norte e Sul acerca do conteúdo (i.e. a norma jurídica) que concerne ao princípio: em breve suma, todos reconhecem sua existência, mas o Norte denega a interpretação sulista de que há, sim, uma responsabilidade ambiental maior do Norte em função de sua modelagem de industrialização pretérita. Já o Sul ignora a interpretação nortista de que o passado náo importa, mas sim o futuro a partir de troca de modelos desenvolvimentistas, contando com gradientes de ajuda econômica e sistema de transferências e dependências tecnológicas (BEYERLIN ET MARAHUN, 2011, pp.60-61). As discussóes sobre o Protocolo de Quioto, da Convenção Quadro das Naçôes Unidas sobre Mudanças Climáticas, constituem mais um exemplo deste impasse principiológico (em especial, o diálogo não-conclusivo da COP/2009 - Copenhague).

[ONG]

Veja-se que a mesma norma jurídica internacional (que trata de problemas Globais), ainda que devidamente formada, recebe formas, aplicaçôes e exequibilidade diferentes, gerando efeitos diferentes, ao sabor/interesse do sujeito de direitos que a aplica. Estas discrepâncias de entendimento normativo, por vezes, imbricam-se nas estruturas do próprio Estado Nacional (SOUZA SANTOS, 2006, p. 44), gerando até divergências no que os dualistas chamam de Ordem Interna. E, em as gerando, sistemas de responsabilização internacional.

Como forma de evitar este tipo de circunstância, cabe apontarmos o instrumental do Direito Comparado. Salvo melhor descrição, o instrumental do Direito Comparado, como tal posto e desenvolvido:

"Entendida como verdadeira ciência ou ainda apenas como um método [...], o direito comparado passou a se identificar com a pesquisa de um modelo melhor, conduzida mediante a análise temporal e materialmente recortada do modelo estrangeiro, as suas semelhanças e dessemelhanças [...] e, assim, avessa à mera especulação pendente de objetivo acerca dos padróes jurídicos de diversos ordenamentos, o que constituiria puro empirismo ou um exercício erudito [...]. Enfim, a comparação voltou-se para problemas práticos. A tendência que intentamos demonstrar a seguir é o intenso uso do direito comparado, pelos juízes constitucionais nacionais, como método de interpretação concretização (e de realização) constitucional, fenômeno que se desenvolve em várias intensidades e compreende doutrina, legislação e decisões estrangeiras. É importante destacar que o recurso a elementos exógenos já existia, por exemplo, nas colônias. A 
novidade é que atualmente não mais se verifica a recepção, e sim o diálogo enriquecedor do próprio direito interno, em que se percebe que os juízes citam outros sistemas não só para preencher as lacunas ou para tratar de algo novo tal como era feito no período colonial, mas para [buscar como outros juízes responderam quando expostos a um assunto passível de comparação].” (CARDOSO, 2010, p. 471).

Ou seja, o Direito Comparado tem por funçáo dar o mesmo efeito material a normas jurídicas comumente aplicáveis entre os sujeitos de direito de coletividades diferentes.

Para tanto, o Direito Comparado investiga as bases materiais e formais do direito (no caso nacional e/ou subnacional) em questão para que, instrumentalizando-as em uma formulação lógica, cumpra a função de dar aos dois (ou mais) sujeitos de direito internacional a mesma norma jurídica internacional materialmente manifestada e exigível. Lembrando que não basta o mesmo preceito, mas a mesma norma jurídica, é na busca de fontes supra e infraestruturais do direito que o "jurista comparatista” encontrará na abordagem funcionalista do direito comparado uma solução na aplicação e conclusóes harmônicas dos direitos extranacionais (internacional e estrangeiros) (HORBACH, 2015; p. 199).

Tal pensamento muda, inclusive, o papel dos agentes externos tanto ao evidenciar às Cortes nacionais (ou subnacionais) a harmônica interpretação da norma internacional, como a influenciar o órgão produtor de preceitos os adequados instrumentos à produção do resultado normativo pretendido.

Somando estes conceitos à ideia já exposta de ONG como veículos, na Corte e Parlamentos, de informaçóes e posiçóes sociais no processo de produção de normas jurídicas, começamos a ter todos os fatores da equação necessários a desenhar uma sintaxe entre Direito Internacional, Direito Comparado e Organizaçóes Não-Governamentais.

Como ONG, em seu vetor nas zonas permeáveis de formação da norma jurídica internacional (i.e. estruturação do preceito internacional e julgamento de Cortes) podem ajudar na missão do Direito Comparado?

\section{A sintaxe entre direito internacional, direito comparado e organizaçóes náo- governamentais}

De todo o posto, e ainda que exsurjam outras indagações (que serão exploradas oportunamente em outros trabalhos), observamos que os atores outros que os Estados Soberanos, em especial as Organizaçóes Não-Governamentais, possuem papéis preponderantes também na escolha as bases materiais e formais do direito (no caso nacional e/ou subnacional) em questão para que, instrumentalizando-as em uma formulação lógica e formal, dois (ou mais) sujeitos de direito internacional sujeitem-se a 
mesma e melhor norma jurídica internacional materialmente manifestada (em função do bem jurídico que visa atingir). E por que este papel é destinado a este tipo de organização?

Aponta-se algumas características inerentes a estas ONG que permitem o desempenho deste papel de nutrir as bases materiais de interpretação (o valor "Ético" de Dworkin) de forma muito mais eficiente que qualquer outro tipo de organização (em especial, Estados Nacionais e Subnacionais), porquê:

a) Sua pertinência temática/direcionamento de objetivos e ideias as tornam desejáveis e aceitas na formulação de normas internacionais, bem como na tomada de decisão (a partir destas normas, inclusive) (GONÇALVES et. Al:: 2011, pp. 6869). Esta especialização carreia ao tomador de decisão (em execução às normas ou à própria formulação) um alento técnico legítimo ao processo construtivo da norma jurídica. Quando houve a necessidade, no Caso 17 (Responsabilidade Ambiental por Mineração na Leito Martinho Inernacional) e no Southern Bluefin Tuna Case (ambos do Tribunal Internacional para o Direito do Mar), as Cortes Internacionais não exitaram em se consultar exaustivamente com órgáos não estatais e não governamentais acerca dos paradigmas científicos e motivaram suas decisões declaradamente nelas, como bem aponta e explora o Grefier da Corte Phillipe Gautier (2016, n.p.);

b) Além da técnica e/ou ciência, a busca pelo "paradigma ético" informativo da norma jurídica também perpassa pela $\mathrm{ONG}$, na qualidade de representante de um grupo de pressão. Em analogia perfeita à Teoria da Firma (COASE, 1937, 366-405.), a ONG é a entidade instrumental de efetivação e otimização da força de um grupo de pressão, de uma opinião pública, que deseja prevalecer politicamente sobre outras (PEREIRA, 2005, 19-22). Esta especialização carreia ao tomador de decisão (em execução às normas ou à própria formulação) uma base de valores infraestruturais útil ao processo construtivo da norma jurídica (em relação aos proveitos que ele pode obter). Um exemplo dessa circunstância é o efeito da pressão das NGO direcionar a aplicação do orçamento público dos EEUU à ajuda internacional (de alívio, humanitária, ambiental, etc.) (KIM, 2017, 112-132).

c) A não-vinculação às amarras administrativas e/ou procedimentais formais que um sujeito de direitos em direito internacional possui, seja um Estado-Naçáo, seja a Organização Internacional. Esta carência de amarras, contraponto ao (por vezes) não reconhecimento como sujeito de direitos no mesmo palco, permite à ONG uma mobilidade e velocidade na consecução de seus trabalhos maior que os demais. O processo de toma de decisão é mais célere, criando vantagem sobre os demais atores e carreando responsabilidades (e.g. Governança) cada vez maiores ao ator ONG. (BEYERLIN ET MARAHUN, 2011, 256-263).

Desta forma, enquanto o papel do Estado será o de negociar e construir a norma internacional, além de internalizá-la de forma harmônica, será papel das ONG 
informar este Estado para: a) eleger a via formal específica, nacional einternacionalmente, considerando as características jurídicas peculiares a cada sistema e país; e b) eleger as interferências ou aproveitamentos das infraestruturas (bases naturais, sociais, culturais e econômicas) que suportarão referida norma jurídica internacional, quando interna.

Daí que, outra conclusão genérica e em paralelo, refere-se que a adoção do preceito estrangeiro (de direito internacional ou até de direito interno) no direito interno sem a devida análise de Direito Comparado gera teratologias em função de sua desconexão com a base infraestrutural.

Estas teratologias prejudicam tanto o universo jurídico positivado em si, como à materialidade de qualquer direito que se intente positivar e objetivar, i.e. o bem jurídico tutelado. Neste senso, tanto o pós-positivismo (nossa base de trabalho) quanto o hermético neopositivismo concordam quanto à não-aplicabilidade da norma, divergindo apenas quanto à natureza jurídica desta não-aplicabilidade, leia-se:

Como a vigência da norma pertence à ordem do dever-ser, e não à ordem do ser, deve também distinguir-se a vigência da norma da sua eficácia, isto é, do fato real de ela ser efetivamente aplicada e observada, da circunstância de uma conduta humana conforme à norma se verificar na ordem dos fatos. Dizer que uma norma vale (é vigente) traduz algo diferente do que se diz quando se afirma que ela é efetivamente aplicada e respeitada, se bem que entre vigência e eficácia possa existir uma certa conexão. Uma norma juríudica é considerada como objetivamente válida apenas quando a conduta humana que ela regula lhe corresponde efetivamente, pelo menos numa certa medida. Uma norma que preceituasse um certo evento que de antemáo se sabe que necessariamente se tem de verificar, sempre e em toda a parte, por força de uma lei natural, seria táo absurda como uma norma que preceituasse um certo fato que de antemão se sabe que de forma alguma se poderá verificar, igualmente por força de uma lei natu-ral. Vigência e eficácia de uma norma jurídica também não coincidem cronologica-mente. Uma norma jurídica entra em vigor antes ainda de se tornar eficaz, isto é, an-tes de ser seguida e aplicada. Um tribunal que aplica uma lei num caso concreto imediatamente após a sua promulgação - portanto, antes que tenha podido tornar-se eficaz - aplica uma norma jurídica válida. Porém, uma norma jurídica deixará de ser considerada válida quando permanece duradouramente ineficaz. A eficácia é, nesta medida, condição da vigência, visto ao estabelecimento de uma norma se ter de se-guir a sua eficácia para que ela não perca a sua vigência. (KELSEN. 1999, p. 8);

Resulta-se o critério seguinte de que se trata o direito: uma proposição de direito é verdadeira se ela aparece como a melhor interpretaçáo do processo jurídico em sua inteireza, compreendendo em única leva o panorama de decisóes já feitas e a estrutura instuticional de onde ela se levanta a toma esta interpretaçáo. Nós vamos pesquisar a concepçáo do direito que implica da aceitação de uma exigência em ver a teoria do direito como uma unidade diferente do convencionalismo e do pragmatismo dos conselhos dados aos juízes para resolver os "casos difíceis" do tipo que vamos evocar. (tradução livre) (DWORKIN, 1985. p. 62).

A vista destas perspectivas de entendimento do fenômeno jurídico, do papel construtivo do Direito Comparado e das ONG desempenhando os obreiros deste papel,. 
temos justificada a asserção do início deste trabalho: porque a Sociedade Internacional tende a abandonar modelos binding para modelagens de soft law (como das ODS 2030).

As normas do tipo "Quadro" e as normas Codificadas não tem condiçôes de cumprir a própria necessidade peculiar de abordagem do objeto ambiental global. Não, ao menos, isolaadamente consideradas. Carlarne $(2014,19-23)$ e Beyerlin et Marahun (2011, 441-446) enunciam razões de relevância:

- A norma jurídica internacional deve permitir um poder de ação, de força, baseado no coletivo, e não em pilar de poder individuais;

- A norma tender à formação de mecanismos de cooperação, e afastar de mecanismos de confrontação;

- A norma tende a buscar controles preventivos ao invés de repressivos;

- A norma deve buscar o compliance e sua assistência, quando falho ou quando apontar não-conformidades, ao invés de mecanismos de sanção.

Esta permeabilidade das soft law às $\mathrm{ONG}$, em função das necessidades de eficácia à proteção do bem jurídico internacional coletivo e inerências da soft law em atendêlas, facilita a obra do Direito Comparado em sintentizar em norma jurídica (interna ou internacional) o desejo da Sociedade Internacional e Interna.

\section{Consideraçóes finais}

Entende-se que o Direito Comparado não olvida, mas, sim, aproveita-se de ONG para cumprimento de sua finalidade, em especial na padronização da materialidade de normas jurídicas internacionais (inclusive no seu atual movimento de incremento de soft law formulada em objetivos e checkpoints).

Este papel das ONG deriva de suas características inerentes, necessárias à produção de normas jurídicas internas harmonizadas com as internacionais (ou delas em replicação/ internalização), mais próxima ao problema Global a ser abordado.

Que a correta aplicação informada do Direito Comparado em Direito Internacional visa, sobretudo, evitar: a) gerar prejuízo tanto o universo jurídico positivado em si, como à materialidade de qualquer direito que se intente positivar e objetivar quanto à nãoaplicabilidade da norma; b) que a mesma norma jurídica internacional (que trata de problema Global), ainda que devidamente formada, receba aplicaçóes e exequibilidade diferentes, gerando efeitos diferentes, ao sabor/interesse do sujeito de direitos que a aplica. 


\section{Referências}

AMARAL, Antonio Carlos Rodrigues do. Ética social e governamental: Advocacy e Lobby. São Paulo: Hottopos, 1997.

ARANGIO-RUIZ, Gaetano. Le Domain Réservé: L'Organisation Internationale et le Rapport entre le Droit International et Droit Interne. In: Cours Général de Droit International Public. Hague: The Hague Academy of International Law, 1990. pp. 444451.

BEYERLIN et. al. International Environmental Law. Oxford: Hart Publishing, 2011.

CARDOSO, Gustavo Vitorino. O Direito Comparado na Jurisdição Constitucional. Revista Direito GV, São Paulo, v.6., n.2., pp. 469-492, jul-dez 2010.

CARLARNE, Cinnamon. Delinking International Environmental Law \& Climate Change. Michigan Journal of Environmental \& Administrative Law, Michigan, v. 4., n.1. 2014. Disponível em: http://repository.law.umich.edu/mjeal/vol4/iss1/1. Acesso em: 9 jun. 2018. pp.1-60

COASE, Ronald H. The Nature of the Firm. Economica. London, v. 4., n.16. 1937. pp. 366-405.

DWORKIN, Ronald. La Chaîne du Droit. Droit et Société: Revue Internationale de Théorie du Droit et de Sociologie Juridique. Paris: LGDJ, 1985.

GAUTIER, Philippe. Le règlement des différends relatifs au droit de la mer et la protection du milieu marin. IN Lecture Series: Law of the Sea. UN: Nova Iorque, 2016. s/p.

GONÇALVES, Alcindo et. al. Governança global e regimes internacionais. São Paulo: Almedina, 2011.

GUERRA, Sidney. Curso de Direito internacional público. São Paulo: Saraiva, 2016.

HARDIN, Garret. The Tragedy of Commons. IN Science, New Series, Vol. 162, No. 3859. Nova Iorque: American Association for the Advancement of Science, 1968. p. 1243-1248. Disponível em: https://science.sciencemag.org/content/ sci/162/3859/1243.full.pdf. Acesso em: 1 abr. 2020.

HORBACH, Carlos Bastide. O Direito Comparado no STF: internacionalização da jurisdição da jurisdição constitucional brasileira. Revista de Direito Internacional, Brasília, v. 12, n. 2, 2015. pp. 469-492.

KELSEN, Hans. Teoria Pura do Direito. São Paulo: Martins Fontes, 1999.

KIM, Youngwan. How NGOs Influence US Foreign Aid Allocations. In: Foreign Policy Analysis. V. 13. I. 1. Oxford: Oxford Academic, 2017. p. 112-132. 
LAWAND JUNIOR, Antonio Elian. Democracia e Legitimidade nos Modelos Atuais de Controle Concentrado de Constitucionalidade. Revista da Faculdade de Direito da Universidade Federal de Goiás, Goiânia, v. 36, n.1., 2012. pp. 205-224.

PEREIRA, Paulo Trigo. Governabilidade, grupos de pressão e o papel do Estado. In: I Encontro Nacional de Ciência Política - Fundaçâo Calouste Gulbenkian. Lisboa: 2005. Disponível em: http://pascal.iseg.utl.pt/_ptrigo/docs/GruposPresaao5.pdf. Acesso em: 28 dez. 2005.

SACHS, Jeffrey. The Age of Sustainable Development. New York: Columbia University Press, 2015. pp. 490-496.

SOUZA SANTOS, Boaventura de. The Heterogeneous State and Legal Pluralism in Mozambique. Law \& Society Review, Hoboken, v. 40, n.1. 2006.

VIDAL, John. The Guardian. Many treaties to save the earth, but where's the will to implement them? London, 2012. Disponível em: https://www.theguardian.com/ environment/blog/2012/jun/07/earth-treaties-environmental-agreements. Acesso em: 9 jun. 2018. 